\title{
Variabilidade espacial do microclima de um galpão utilizado para confinamento de bovinos de leite
}

\author{
Climatic spatial variability of a dairy freestall barn
}

\author{
Flaviane Flor de Faria' ${ }^{\mathrm{I}}$ Daniella Jorge de Moura' ${ }^{\mathrm{II}}$ Zigomar Menezes de Souza ${ }^{\mathrm{II}}$ \\ Soraia Vanessa Matarazzo ${ }^{\text {III }}$
}

\section{RESUMO}

O conhecimento da variabilidade espacial de atributos climáticos e a construção de mapas de krigagem podem auxiliar no manejo adequado de animais confinados em galpões. Portanto, o trabalho teve como objetivos caracterizar a variabilidade espacial do microclima de um galpão do tipo free-stall utilizado para confinamento de bovinos leiteiros empregando a técnica de geoestatística e verificar se as variáveis climáticas encontram-se dentro dos limites de conforto dos animais. Os atributos microclimáticos temperatura, umidade relativa, velocidade do vento, luminosidade e índice de temperatura e umidade (ITU) - foram amostrados em 152 pontos, em intervalos regulares de $2 \mathrm{~m}$, na forma de malha. Por meio dos resultados obtidos, foi possível verificar que o uso da geoestatística possibilitou definir áreas com diferentes variabilidades espaciais para os atributos microclimáticos, definindo áreas específicas no galpão onde a umidade relativa, a temperatura, a velocidade do vento e a luminosidade estão acima do recomendado para o conforto térmico animal. O sistema de climatização utilizado não garantiu a homogeneização do ambiente. Os valores de ITU permaneceram fora da condição de conforto térmico, portanto, a condição de ambiência do galpão possivelmente não propicia conforto aos animais.

Palavras-chave: geoestatística, mapa de isolinhas, ambiência animal, instalações.

\section{ABSTRACT}

The knowledge of the spatial variability of climatic attributes and the build of kriging maps can help livestock management in lodged animals. Therefore, the objective of this research was to characterize the spatial variability of the

\begin{abstract}
climatic attributes inside a dairy cow free-stall barn using the technique of geostatistics and to verify if the climatic variables are in agreement with the thermal comfort limits of the animals. The climatic attributes - temperature, relative humidity, wind speed, luminosity and temperature and humidity index (THI) were sampled in 152 points, in regular spacing of $2 m$, as a grid. According the results, the geostatistical analysis made it possible to find areas with different spatial variability for the climatic variables, showing specifically areas inside the dairy barn where the relative humidity, the temperature, the air velocity and the luminosity were above that the comfort limits for animal housing. The acclimatization system didn't homogenize the environment. The THI values remained above the thermal comfort condition, so, the environment of the barn probably didn't provide comfort for the animals.
\end{abstract}

Key words: geostatistics, kriging maps, animal environment, building.

\section{INTRODUÇÃO}

O aumento da produtividade dos rebanhos leiteiros no Brasil tem sido obtido com a introdução de animais geneticamente desenvolvidos em climas temperados. Esses animais, especializados em produção de leite, possuem metabolismo elevado, com produção de maior quantidade de calor endógeno (SOUZA et al., 2004). Isso justifica em parte a crescente preocupação com o conforto animal, já que o Brasil é um país predominantemente de clima tropical, com temperaturas

'Departamento de Construções Rurais, Faculdade de Engenharia Agrícola (FEAGRI), Universidade Estadual de Campinas (UNICAMP), CP 6011, 13083-875, Campinas, SP, Brasil. E-mail: flaviane@gmail.com.

"Faculdade de Engenharia Agrícola (FEAGRI), Universidade de Campinas (UNICAMP), Campinas, SP, Brasil. E-mail: zigomarms@agr.unicamp.com.br. *Autor para correspondência.

IIIInstituto de Zootecnia (IZ), Nova Odessa, SP, Brasil. 
médias elevadas durante o ano na maior parte do seu território. As altas temperaturas, quando associadas à alta umidade relativa em galpões de confinamento projetados inadequadamente, contribuem ainda mais para o baixo desempenho do rebanho leiteiro sob condições de estresse térmico.

O manejo do ambiente tem sido amplamente difundido, no sentido de melhorar as condições de conforto do animal, em função da influência dos atributos climáticos em favorecer ou prejudicar o seu desempenho. Este manejo engloba as estratégias usadas para reduzir os problemas existentes na relação animal-ambiente. Em climas quentes e úmidos, o uso de modificações ambientais, primárias ou secundárias, torna-se necessário ao combate do estresse térmico dos animais, permitindo que eles possam produzir e reproduzir com eficiência (BAÊTA \& SOUZA, 1997). Tais modificações permitem que os animais tenham maior grau de bem-estar.

Em alguns sistemas de produção de leite, usa-se a aspersão de água combinada a ventiladores, para aliviar o estresse por altas temperaturas. Experimentos demonstram que, com esta prática, vacas holandesas produziram 7,1\% a mais de leite em Israel e 15,8\% a mais no Kentucky, Estados Unidos (BUCKLIN et al., 1991; COLLIER et al., 2006). PERISSINOTTO et al. (2006), estudando o efeito da utilização de sistemas de climatização nos parâmetros fisiológicos do gado leiteiro, verificaram que os sistemas de resfriamento, nebulização e aspersão, ambos associados à ventilação forçada, reduziram significativamente a temperatura máxima do abrigo em relação à temperatura do ambiente externo.

Quando uma variável se difere de um local para outro com algum grau de continuidade, expresso pela dependência espacial, a geoestatística possibilita uma visão espacial útil ao planejamento e ao controle das informações do ambiente de produção, permitindo a interpolação por meio da krigagem, apresentando a vantagem de fornecer mapas de isolinhas precisos (VIEIRA, 2000). A modelagem geoespacial e a interpolação por krigagem permitem a descrição quantitativa da variabilidade espacial de atributos microclimáticos de galpões de confinamento de gado leiteiro e a estimativa não-tendenciosa, com variância mínima de valores desses atributos em locais nãoamostrados.

Conhecer a variabilidade espacial do microclima de galpões de confinamento na bovinocultura leiteira é um fator indispensável. Atributos como temperatura, umidade relativa, luminosidade e ventilação natural e artificial influenciam no comportamento, no bem-estar e na produtividade dos animais confinados em galpões. Portanto, o conhecimento da variabilidade espacial destes atributos e a construção de mapas de krigagem podem auxiliar no manejo correto de animais confinados em galpões do tipo free-stall. Dentro desse contexto, o trabalho teve como objetivos caracterizar a variabilidade espacial do microclima de um galpão do tipo free-stall utilizado para confinamento de bovinos leiteiros e verificar se as variáveis climáticas encontramse dentro dos limites de conforto dos animais.

\section{MATERIAL E MÉTODOS}

O experimento foi realizado no município de Nova Odessa, São Paulo, com coordenadas geográficas de $22^{\circ} 42^{\prime}$ de latitude sul e $47^{\circ} 18^{\prime}$ 'de longitude oeste e com altitude média de $540 \mathrm{~m}$. A pluviosidade média anual característica da região é de $1.270 \mathrm{~mm}$. Os dados foram coletados em um galpão free-stall contendo 20 baias, onde são alojadas 20 vacas em produção leiteira da raça Holandesa, com 36,0m de comprimento e 14,0m de largura, orientação norte-sul, laterais abertas, pé-direito de 3,0m, telhado de duas águas com cobertura de telhas cerâmicas, e piso de concreto ranhurado para melhor escoamento da água e de dejetos.

O trabalho foi conduzido no mês de janeiro de 2007. As coletas dos dados foram realizadas nos dias 11, 16 e 23 de janeiro com altas temperaturas em horários críticos (12h às 15h). Para a medição dos atributos climáticos, os aparelhos foram mantidos a uma mesma altura (1,5m do piso). O galpão foi avaliado com animais nas seguintes situações de sistema de climatização: ambiente 1 - sem ventilação e sem nebulização; ambiente 2 - com ventilação forçada e sem nebulizador e ambiente 3 - com ventilação forçada associada a sistema de nebulização.

A ventilação forçada, em ambos os tratamentos, foi realizada com três ventiladores axiais da marca CASP ${ }^{\circledR}$ VA 92 plus, espaçados a cada $11 \mathrm{~m}$, equipados com motor de $1 / 2 \mathrm{cv}$, com capacidade de produzir movimentação de ar de até $2,5 \mathrm{~m} \mathrm{~s}^{-1}$ em um raio de 14 a $15 \mathrm{~m}$, na altura do dorso dos animais. O sistema de nebulização foi instalado logo abaixo dos ventiladores, sobre o cocho de alimentação dos animais, sendo constituído por tubos de PVC, com espaçamento entre bicos de $1 \mathrm{~m}$ e, assim como os ventiladores, tiveram seu funcionamento controlado por um termostato e um timer. O sistema era acionado quando a temperatura ambiente ultrapassava $24^{\circ} \mathrm{C}$.

Os atributos microclimáticos temperatura, umidade relativa, velocidade do vento e luminosidade foram coletados em uma malha regular com 152 pontos, distribuídos uniformemente ao longo do galpão com 
espaçamento de $2 \mathrm{~m}$ entre cada ponto. O equipamento utilizado para coleta dos dados foi o Higrotermoanemômetro decibelímetro portátil da marca Instrutherm, Modelo THDL - 400. Esse equipamento permite a medição da temperatura entre $20^{\circ} \mathrm{C}$ e $750^{\circ} \mathrm{C}$, umidade relativa entre $25 \%$ e $95 \%$, velocidade do vento de 0,4 a $30,0 \mathrm{~m} \mathrm{~s}^{-1}$ e luminosidade na faixa entre 0 e 20.000lux.

A partir dos dados meteorológicos coletados, foi obtido o Índice de Temperatura e Umidade (ITU), que, de acordo com BUFFINGTON et al. (1981), é um índice comumente utilizado para avaliar o estresse térmico do gado leiteiro. O ITU para os 152 pontos do galpão para cada dia de coleta de dados foi inicialmente calculado obtendo-se o ponto de orvalho para esses pontos, a partir de uma carta psicrométrica e dos dados de temperatura e umidade relativa coletados, de acordo com a equação 1 :

ITU $=$ Tbs + 0,36Tpo $+41,7$

em que Tbs - temperatura de bulbo seco, ${ }^{\circ} \mathrm{C}$, e Tpo temperatura de ponto de orvalho, ${ }^{\circ} \mathrm{C}$.

Os atributos microclimáticos foram avaliados por meio da análise estatística descritiva calculando-se a média, a mediana, o coeficiente de variação, o coeficiente de assimetria e o coeficiente de curtose. A hipótese de normalidade dos dados foi testada pelo teste de Kolmogorov-Smirnov, por meio do programa computacional SAS (SCHLOTZHAVER \& LITTELL, 1997).

A dependência espacial foi analisada por meio de ajustes de semivariogramas (VIEIRA, 2000), com base na pressuposição de estacionariedade da hipótese intrínseca, a qual é estimada por:

$$
\hat{\gamma}(h)=\frac{1}{2 N(h)} \sum_{i=1}^{N(h)}\left[Z\left(x_{i}\right)-Z\left(x_{i}+h\right)\right]^{2}
$$

em que $N$ (h) é o número de pares experimentais de observações $\mathrm{Z}\left(\mathrm{x}_{\mathrm{i}}\right)$ e $\mathrm{Z}\left(\mathrm{x}_{\mathrm{i}}+\mathrm{h}\right)$ separados por uma distância h. O semivariograma é representado pelo gráfico $\hat{\gamma}(h)$ versus h. Do ajuste de um modelo matemático aos valores calculados de são estimados os coeficientes do modelo teórico para o semivariograma (o efeito pepita, $\mathrm{C}_{0}$; patamar, $\mathrm{C}_{0}+\mathrm{C}_{1}$; e o alcance, a). Para analisar o grau da dependência espacial dos atributos em estudo, utilizou-se a classificação de CAMBARDELLA et al. (1994), em que são considerados de dependência espacial forte os semivariogramas que têm um efeito pepita $<25 \%$ do patamar, moderada quando está entre 25 e $75 \%$ e fraca $>75 \%$.

Os modelos de semivariogramas considerados foram o esférico, o exponencial, o linear e o gaussiano, sendo ajustados por meio do programa $\mathrm{GS}^{+}$e, posteriormente, tais modelos foram usados no desenvolvimento de mapas de isolinhas (krigagem). Em caso de dúvida entre mais de um modelo para o mesmo semivariograma, considerado o maior valor do coeficiente de correlação obtido pelo método de validação cruzada. Para elaboração dos mapas de distribuição espacial das variáveis, foi utilizado o programa Surfer. Os mapas gerados no Surfer foram exportados para o programa Idrisi Kilimanjaro, no qual foram calculadas as áreas que cada classe dos atributos microclimáticos estudados apresentava em relação à área total.

Foi realizada a análise exploratória dos dados para cálculo dos momentos estatísticos dos diferentes atributos climáticos avaliados empregando o método não-paramétrico de Kruskal-Wallis para verificação das diferenças entre médias das parcelas, duas a duas. Posteriormente, foi empregado o teste de Dunn's, com 5\% de probabilidade, para testar a significância das diferenças entre medianas. As análises estatísticas foram efetuadas utilizando o programa SAS (SCHLOTZHAVER \& LITTELL, 1997).

\section{RESULTADOS E DISCUSSÃO}

De acordo com os resultados obtidos com o teste de normalidade Kolmogorov-Smirnov, apenas a variável ITU do ambiente 1 indicou normalidade (Tabela 1). Apesar da ocorrência de algumas distribuições assimétricas, o valor da média e mediana de todos os atributos microclimáticos estudados são próximos, com exceção das variáveis velocidade do vento e luminosidade, mostrando que os dados não apresentam assimetria acentuada. Segundo LITTLE \& HILLS (1978), quando o valor da média, da mediana e da moda estão semelhantes, os dados apresentam ou se aproximam da distribuição normal. Isso pode ser um indicativo de que as medidas de tendência central não são dominadas por valores atípicos na distribuição (CAMBARDELLA et al., 1994). Segundo ISAAKS \& SRIVASTAVA (1989) mais importante que a normalidade dos dados é a ocorrência do efeito proporcional em que a média e a variância dos dados não sejam constantes na área de estudo e este fato não ocorreu, visto que os semivariogramas apresentaram patamares bem definidos.

O método não-paramétrico de KruskalWallis mostrou diferença significativa para todas as variáveis climáticas estudadas, com exceção da variável luminosidade. Observa-se que o ambiente 1 (sem ventilação e sem nebulização) diferiu do ambiente 2 (com ventilação e sem nebulização) e do ambiente 3 (com ventilação e com nebulização). A nebulização reduziu significativamente a temperatura do ambiente, 
Tabela 1 - Estatística descritiva para os atributos microclimáticos temperatura $\left({ }^{\circ} \mathrm{C}\right)$, umidade relativa (\%), velocidade do vento (m $\left.\mathrm{s}^{-1}\right)$, luminosidade (lux) e índice de temperatura e umidade (ITU) nos diferentes ambientes estudados em galpão com o sistema freestall.

\begin{tabular}{|c|c|c|c|c|c|c|}
\hline Variáveis & Média & Mediana & ${ }^{1} \mathrm{CV}$ & Assimetria & Curtose & ${ }^{2} \mathrm{~d}$ \\
\hline & \multicolumn{6}{|c|}{ Ambiente 1} \\
\hline Temperatura & 32,78 & ${ }^{4} 31,80 \mathrm{a}$ & 2,15 & 0,80 & 0,50 & 0,12 \\
\hline Umidade relativa & 47,62 & $48,65 \mathrm{~b}$ & 14,87 & $-2,43$ & 5,96 & 0,25 \\
\hline Velocidade do vento & 0,33 & $0,10 \mathrm{a}$ & 150,96 & 1,91 & 1,78 & 0,25 \\
\hline Luminosidade & 995,13 & $340,00 \mathrm{a}$ & 178,50 & 1,78 & 1,36 & 0,33 \\
\hline \multirow[t]{2}{*}{${ }^{3} \mathrm{ITU}$} & 80,02 & 79,98 a & 1,21 & 1,21 & 2,71 & $0,08^{\text {ns }}$ \\
\hline & \multicolumn{6}{|c|}{ Ambiente 2} \\
\hline Temperatura & 33,40 & $33,20 \mathrm{a}$ & 4,64 & 0,39 & $-0,93$ & 0,14 \\
\hline Umidade relativa & 26,19 & $26,80 \mathrm{c}$ & 14,54 & $-0,20$ & $-1,23$ & 0,15 \\
\hline Velocidade do vento & 0,29 & 0,19 a & 161,22 & 1,98 & 3,68 & 0,27 \\
\hline Luminosidade & 787,23 & $303,01 \mathrm{a}$ & 217,77 & 4,28 & 9,16 & 0,38 \\
\hline \multirow[t]{2}{*}{ ITU } & 78,77 & $78,48 \mathrm{~b}$ & 2,13 & 0,23 & 0,32 & 0,14 \\
\hline & \multicolumn{6}{|c|}{ Ambiente 3} \\
\hline Temperatura & 29,21 & $29,90 \mathrm{~b}$ & 6,18 & 0,02 & $-0,93$ & 0,16 \\
\hline Umidade relativa & 56,38 & 54,65 a & 17,39 & $-0,03$ & 1,17 & 0,19 \\
\hline Velocidade do vento & 0,11 & $0,07 \mathrm{~b}$ & 242,72 & 2,64 & 6,12 & 0,29 \\
\hline Luminosidade & 373,65 & 295,42 a & 105,96 & 0,99 & $-0,05$ & 0,28 \\
\hline ITU & 79,14 & $79,29 \mathrm{ab}$ & 1,94 & 0,49 & 1,20 & 0,15 \\
\hline
\end{tabular}

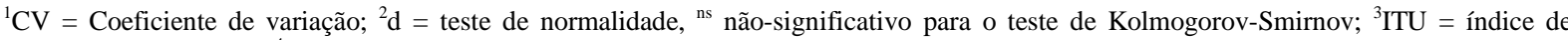
temperatura e umidade. ${ }^{4}$ Medianas seguidas de mesma letra minúscula, não diferem entre si em nível de 5\% de probabilidade, pelo teste de Dunn's.

resultado semelhante ao verificado por PERISSINOTTO et al. (2006), estudando o efeito da utilização de sistemas de climatização nos parâmetros fisiológicos do gado leiteiro em um galpão free-stall. A umidade relativa foi significativamente maior nos ambientes 1 e 3 em relação ao ambiente 2 . O ambiente 3 apresentou menor valor para o vento quando comparado com os demais ambientes estudados. Para a variável ITU, nota-se que o ambiente 2 apresentou diferença significativa em relação aos ambientes 1 e 3 .

Os valores para temperatura do ar mostraramse acima do ideal para vacas em lactação, nos três ambientes estudados, os quais, segundo HUBER (1990), estão entre $4^{\circ} \mathrm{C}$ e $26^{\circ} \mathrm{C}$. Os valores do índice de temperatura e umidade (ITU) apresentaram-se acima dos limites para caracterização de situações de alerta, para todos os ambientes estudados. A situação de alerta é caracterizada com intervalos que divergem entre os autores, sendo considerada entre 75 e 78 (ROSEMBERG et al., 1983) e acima de 76, segundo IGONO \& JOHNSON (1992). Segundo JOHNSON (1980), a partir do valor de ITU de 72 e na medida em que este índice se elevou, a produção de leite foi declinando, sendo este declínio mais acentuado nas vacas mais produtoras.

Coeficientes de variação (CV) são adimensionais e valores elevados de $\mathrm{CV}$ podem ser considerados como os primeiros indicadores da existência de heterogeneidade nos dados (Tabela 1). Aoserem considerados os critérios de classificação de WARRICK \& NIELSEN (1980), os atributos microclimáticos temperatura e ITU apresentaram baixa variabilidade $(\mathrm{CV}<12 \%)$ nos três ambientes estudados, a umidade relativa teve média variabilidade $(12 \%<\mathrm{CV}>24 \%)$ e as variáveis velocidade do vento e luminosidade alto coeficiente de variação ( $C V>24 \%)$.

A alta variabilidade da velocidade do vento deve-se ao fato de que o vento é caracterizado por mudar sua magnitude e direção constantemente com variações de até $100 \%$ na média da magnitude num intervalo de cinco minutos. Já a alta variabilidade da luminosidade ocorreu porque no galpão havia locais nos quais a radiação solar incidia diretamente, devido à orientação norte-sul. Assim, os pontos de coleta mais próximos a uma das porteiras de entrada e nos pontos em uma das laterais do galpão apresentaram alta luminosidade quando comparada à luminosidade do interior do galpão, como pode ser visualizado no mapa de distribuição espacial (Figura 1). Segundo VANNI (1998), um coeficiente de variação maior que 35\% revela que a série é heterogênea e a média tem pouco significado. Dessa forma, pode-se dizer que os atributos microclimáticos velocidade do vento e luminosidade apresentaram série de dados heterogêneos e a média tem pouco significado. 


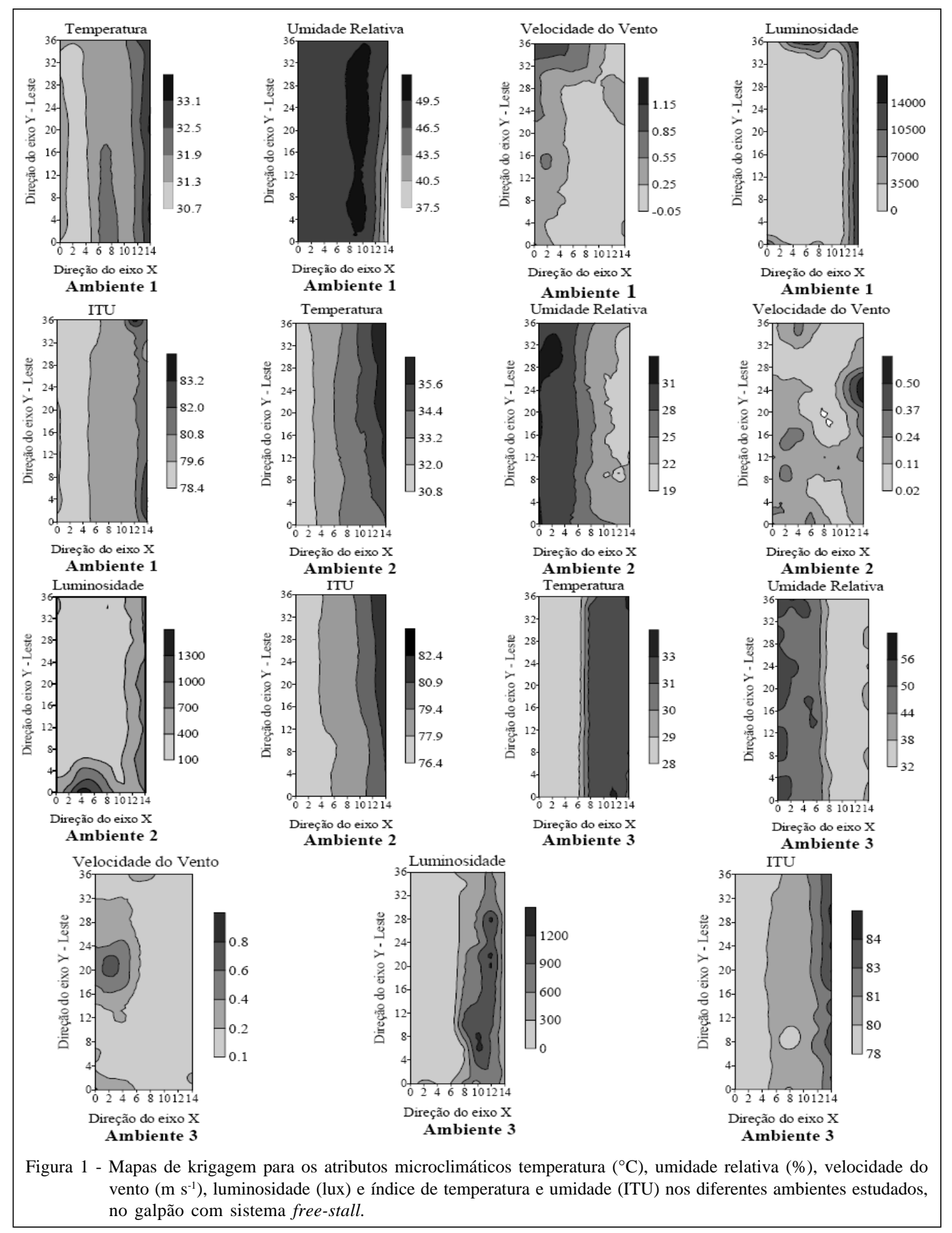

Os resultados da análise geoestatística mostraram que todos os atributos microclimáticos estudados nos diferentes ambientes apresentaram dependência espacial (Tabela 2). A análise dos semivariogramas para os atributos climáticos não indicou nenhuma direção preferencial, ou seja, como afirma VIEIRA (2000), nesse caso, os dados não possuem anisotropia, a variabilidade espacial dos dados ocorre da mesma maneira em todas as direções. MILES et al. (2008), estudando a variabilidade temporal e a variabilidade espacial de compostos de nitrogênio e atributos climáticos de um galpão de frango de corte, com o uso da ferramenta geoestatística e confecção de 
Tabela 2 - Modelos e parâmetros estimados dos semivariogramas experimentais para os atributos microclimáticos temperatura ( ${ }^{\circ} \mathrm{C}$ ), umidade relativa (\%), velocidade do vento $\left(\mathrm{m} \mathrm{s}^{-1}\right)$, luminosidade (lux) e índice de temperatura e umidade (ITU) nos diferentes ambientes estudados no galpão com sistema free-stall.

\begin{tabular}{|c|c|c|c|c|c|c|}
\hline Atributos & Modelo & Efeito pepita & Patamar & Alcance & ${ }^{1} \mathrm{C}_{0} /\left(\mathrm{C}_{0}+\mathrm{C}_{1}\right)$ & ${ }^{2} \mathrm{R}^{2}$ \\
\hline & \multicolumn{6}{|c|}{ Ambiente 1} \\
\hline Temperatura & Esférico & 0,06 & 0,49 & 14,90 & 12 & 0,87 \\
\hline Umidade relativa & Esférico & 7,30 & 19,60 & 15,60 & 37 & 0,91 \\
\hline Velocidade do vento & Esférico & 0,08 & 0,16 & 17,10 & 50 & 0,96 \\
\hline Luminosidade & Esférico & 5190000 & 35130000 & 16,20 & 15 & 0,92 \\
\hline \multirow[t]{2}{*}{${ }^{3} \mathrm{ITU}$} & Esférico & 0,10 & 1,10 & 15,90 & 9 & 0,90 \\
\hline & \multicolumn{6}{|c|}{ Ambiente 2} \\
\hline Temperatura & Gaussiano & 0,001 & 3,10 & 24,60 & 1 & 0,90 \\
\hline Umidade relativa & Gaussiano & 0,01 & 17,30 & 21,00 & 1 & 0,91 \\
\hline Velocidade do vento & Exponencial & 0,03 & 0,06 & 14,60 & 50 & 0,77 \\
\hline Luminosidade & Esférico & 1196 & 3051 & 23,20 & 39 & 0,96 \\
\hline \multirow[t]{2}{*}{ ITU } & Esférico & 0,13 & 0,27 & 13,40 & 48 & 0,85 \\
\hline & \multicolumn{6}{|c|}{ Ambiente 3} \\
\hline Temperatura & Esférico & 0,01 & 3,97 & 12,36 & 1 & 0,88 \\
\hline Umidade relativa & Esférico & 0,10 & 63,23 & 12,92 & 1 & 0,94 \\
\hline Velocidade do vento & Esférico & 0,04 & 0,07 & 13,39 & 57 & 0,92 \\
\hline Luminosidade & Esférico & 8200 & 169700 & 10,63 & 5 & 0,89 \\
\hline ITU & Esférico & 0,001 & 3,15 & 13,50 & 1 & 0,90 \\
\hline
\end{tabular}

${ }^{1} \mathrm{C}_{0} /\left(\mathrm{C}_{0}+\mathrm{C}_{1}\right)$ = grau de dependência espacial; ${ }^{2} \mathrm{R}^{2}=$ coeficiente de determinação; ${ }^{3} \mathrm{ITU}=$ índice de temperatura e umidade.

mapas de isolinhas, encontraram dependência espacial para os atributos climáticos.

Todos os semivariogramas dos dados microclimáticos do galpão ajustaram-se ao modelo esférico, com exceção dos atributos microclimáticos temperatura e umidade relativa, que tiveram os dados ajustados ao modelo gaussiano e velocidade do vento, ao modelo exponencial no ambiente 2 (Tabela 2). Estes modelos são considerados transitivos (ISAAKS \& SRIVASTAVA, 1989), pois possuem patamar, ou seja, a partir de um determinado valor da distância entre amostras, não existe mais dependência espacial (a variância da diferença entre pares de amostras tornase invariante com a distância), sendo que resultados semelhantes foram observados por MILES et al. (2008).

O efeito pepita reflete a variabilidade não explicada em função da distância da amostragem utilizada, como variações locais, erros de análise, erros de amostragem e outros. Como é impossível quantificar a contribuição individual desses erros, o efeito pepita pode ser expresso como porcentagem do patamar facilitando, assim, a comparação do grau de dependência espacial das variáveis em estudo (TRANGMAR et al., 1985).

Portanto, a relação $\mathrm{C}_{0} /\left(\mathrm{C}_{0}+\mathrm{C}_{1}\right)$ mostrou que os atributos microclimáticos apresentaram dependência espacial com grau variando de forte a moderado em todos os ambientes estudados (Tabela 2). Com relação ao alcance da dependência espacial, observa-se que os valores dos atributos microclimáticos do ambiente 1 são bastante semelhantes aos valores do ambiente 2 . No ambiente 3, os valores do alcance são inferiores aos obtidos nos ambientes 1 e 2, portanto, a nebulização no galpão aumentou a variabilidade espacial dos atributos microclimáticos.

Observa-se para todos os ambientes em estudo que as maiores temperaturas ocorreram na lateral direita do galpão (Figura 1). Isso se deve ao fato que, nos dias de avaliação, os dados foram coletados por volta das 15 horas e, com a orientação do galpão na direção norte-sul, a radiação solar incidia diretamente sobre a lateral oeste do galpão. Nos ambientes 1 e 3, verifica-se que $87 \%$ e $99 \%$ da área do galpão, respectivamente, apresentaram temperatura abaixo de $32^{\circ} \mathrm{C}$ e no ambiente $282 \%$ da área do galpão apresentou temperatura acima de $32^{\circ} \mathrm{C}$, indicando que o sistema de ventilação não reduziu a temperatura do ambiente em quase toda extensão do galpão (Tabela 3). Porém, mesmo com os equipamentos de climatização, a temperatura encontra-se acima do recomendado, pois, segundo NÄÄS (1998), a faixa de 13 a $18^{\circ} \mathrm{C}$ é termicamente confortável para a maioria dos ruminantes, especificamente para as vacas em lactação, sendo que essa faixa pode estender-se de 4 a $24^{\circ} \mathrm{C}$, restringindo-se aos limites de 7 a $21^{\circ} \mathrm{C}$ em função da umidade relativa do ar e da radiação solar.

Os ambientes apresentaram homogeneidade da umidade relativa em toda a parte oeste do galpão 
Tabela 3 - Porcentagem de área de cada classe para os para os atributos microclimáticos temperatura ( $\left.{ }^{\circ} \mathrm{C}\right)$, umidade relativa $(\%)$, velocidade do vento ( $\mathrm{m} \mathrm{s}^{-1}$ ), luminosidade (lux) e índice de temperatura e umidade (ITU) nos diferentes ambientes estudados, no galpão com sistema free-stall.

\begin{tabular}{|c|c|c|c|c|c|c|c|c|c|}
\hline \multicolumn{10}{|c|}{ Porcentagem de classe (\%) } \\
\hline \multicolumn{10}{|c|}{ 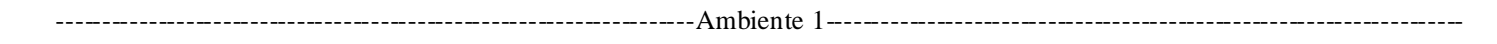 } \\
\hline Classe & Tempe ratura & Classe & Umidade & Classe & Vento & Classe & Luminosidade & Classe & ITU \\
\hline $30,7-31,3$ & 22 & $37,5-40,5$ & 2 & $0,05-0,25$ & 53 & $0-3500$ & 83 & $78,4-79,6$ & 24 \\
\hline $31,3-31,9$ & 49 & $40,5-43,5$ & 1 & $0,25-0,55$ & 24 & $3500-7000$ & 4 & $79,6-80,8$ & 11 \\
\hline $31,9-32,5$ & 16 & $43,5-46,5$ & 3 & $0,55-0,85$ & 9 & $7000-10500$ & 5 & $80,8-82,0$ & 50 \\
\hline $32,5-33,1$ & 4 & $46,5-49,5$ & 79 & $0,85-1,15$ & 8 & $10500-14000$ & 3 & $82,0-83,2$ & 10 \\
\hline$>33,1$ & 9 & $>49,5-$ & 15 & $>1,15$ & 6 & $>14000$ & 5 & $>83,2$ & 5 \\
\hline & & & & An & te 2--- & --------------- & 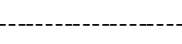 & --_----.-- & \\
\hline $30,8-32,0$ & 18 & $19-22$ & 13 & $0,02-0,11$ & 28 & $100-400$ & 64 & $76,4-77,9$ & 28 \\
\hline $32,0-33,2$ & 23 & $22-25$ & 31 & $0,11-0,24$ & 50 & $400-700$ & 24 & $77,9-79,4$ & 40 \\
\hline $33,2-34,4$ & 33 & $25-28$ & 15 & $0,24-0,37$ & 8 & $700-1000$ & 3 & $79,4-80,9$ & 16 \\
\hline $34,4-35,6$ & 17 & $28-31$ & 34 & $0,37-0,50$ & 8 & $1000-1300$ & 7 & $80,9-82,4$ & 4 \\
\hline$>35,6$ & 9 & $>31$ & 7 & $>0,50$ & 6 & $>1300$ & 2 & $>82,4$ & 12 \\
\hline $28-29$ & 43 & $32-38$ & 40 & $0,1-0,2$ & 78 & $0-300$ & 47 & $78-80$ & 31 \\
\hline $29-30$ & 6 & $38-44$ & 12 & $0,2-0,4$ & 14 & $300-600$ & 18 & $80-81$ & 46 \\
\hline $30-31$ & 5 & $44-50$ & 34 & $0,4-0,6$ & 6 & $600-900$ & 17 & $81-83$ & 16 \\
\hline $31-33$ & 45 & $50-56$ & 14 & $0,6-0,8$ & 2 & $900-1200$ & 16 & $83-84$ & 7 \\
\hline$>33$ & 1 & $>56$ & 0 & $>0,8$ & 0 & $>1200$ & 2 & $>84$ & 0 \\
\hline
\end{tabular}

(Figura 1). Na parte leste dos ambientes 2 e 3, verificase a presença de uma região com umidade relativa maior e uma faixa com umidade relativa bem inferior na extremidade, o que também pode ser observado no ambiente 1, porém, com menor intensidade. Nos ambientes 1 e 3, são observadas as maiores umidades relativas, $100 \%$ e $60 \%$ da área do galpão apresenta umidade relativa acima de $40 \%$, respectivamente, já o ambiente 2 apresentou a menor umidade relativa (Tabela 3).

A velocidade do vento em todo o galpão foi desuniforme e baixa (muito próxima a zero) para todos os ambientes estudados. Isso se deve ao fato que os dias da coleta de dados eram ensolarados, caracterizados por brisa muito fraca e inconstante. No entanto, além da ventilação natural, os ambientes 2 e 3 possuíam também uma ventilação forçada por meio de ventiladores instalados na região Leste do galpão que contribuíram com a ventilação do local. Porém, o sistema de ventilação utilizado não garante a homogeneidade da ventilação do ambiente, uma vez que os mapas de velocidade do vento não apresentam continuidade nos ambientes. Observa-se nos três ambientes estudados que 77\%, 78\% e 92\% da área do galpão apresentam velocidade do vento nas duas classes mais baixas (Tabela 3 ).

Nos ambientes 1, 2 e 3, verifica-se que os pontos de maior luminosidade ocorreram mais ao extremo oeste e na região mais próxima às entradas centrais do galpão (Figura 1). Isso ocorreu devido ao fato de que os dados foram coletados no período da tarde e devido à orientação do galpão (norte-sul). Essa alta luminosidade, oriunda da radiação solar, contribui para a maior temperatura apresentada nessa região. Nota-se, nos três ambientes estudados, que 87\%, 88\% e 65\% da área do galpão apresentam luminosidade nas duas classes mais baixas (Tabela 3).

Os ambientes em estudo apresentaram valores de ITU acima de 76,4, indicando uma situação de perigo de estresse térmico para os animais (Tabela 3 e Figura 1). Verifica-se, nos três ambientes, que 100\%, $72 \%$ e 100\% da área do galpão, respectivamente, estão acima da situação de perigo. No ambiente 2, no extremo leste do galpão, foi observado valor de ITU de 76,4, indicando uma situação crítica, contud,o esse valor ainda é alto para garantir as condições ideais de conforto térmico, uma vez que condições normais expressas por ITUs abaixo de 70 .

Nos ambientes estudados, os valores de ITU estão acima da condição ideal, sendo que $100 \%$ da área dos galpões estão fora das condições ideais de conforto térmico. O ambiente térmico do galpão não se enquadra em condição considerada como de conforto para os animais, podendo promover estresse e redução na produtividade. Segundo HEAD (1995), o principal fator a ser considerado para garantir o conforto ao animal, em países tropicais e subtropicais, é minimizar os efeitos do estresse térmico, pois as condições climáticas nessas regiões constituem o grande desafio 
aos produtores, por alterarem os três processos vitais dos animais: a manutenção, a reprodução e a produção de leite.

\section{CONCLUSÕES}

O uso da geoestatística possibilitou definir áreas com diferentes variabilidades espaciais para os atributos microclimáticos, definindo áreas específicas no galpão onde a umidade relativa, a temperatura, a velocidade do vento e luminosidade estão acima do recomendado para o conforto térmico animal.

O sistema de climatização utilizado não garantiu a homogeneização do ambiente. Os valores de ITU permaneceram fora da condição de conforto térmico, portanto, a condição de ambiência do galpão possivelmente não propicia conforto aos animais.

\section{REFERÊNCIAS}

BAÊTA, F.C.; SOUZA, C.F. Ambiência em edificações rurais - conforto animal. Viçosa: UFV, 1997. 246p.

BUCKLIN, R.A. et al. Methods to relieve heat stress for dairy cows in hot, humid climates. Applied Engineering in Agriculture, St. Joseph, v.7, n.2, p.241-247, 1991.

BUFFINGTON, D.E. et al. Black globehumidity index (BGHI) as comfort equation for dairy cows. Transaction of the ASAE, St. Joseph, v.24, n.3, p.711-714, 1981.

CAMBARDELLA, C.A. et al. Field scale variability of soil properties in Central Iowa soils. Soil Science Society of America Journal, Madison, v.58, n.5, p.1501-1511, 1994.

COLLIER, R.J. et al. Major advances associated with environmental effects on dairy cattle. Journal of Dairy Science, Savoy, v.89, p.1244-1253, 2006.

HEAD, H.H. Management of dairy cattle in tropical and subtropical environments. In: CONGRESSO BRASILEIRO DE BiOMETEOROLOGiA, 2., 1995, Jaboticabal. Anais... Jaboticabal: SBBiomet, 1995. p.26-68.

HUBER, J.T. Alimentação de vacas de alta produção sob condições de estresse térmico. In: PEIXOTO, A.M. et al. Bovinocultura leiteira. Piracicaba: FEALQ, 1990. p.33-48.

IGONO, M.O.; JOHNSON, H.D. Physiologic stress index of lactating dairy cows based on diurnal pattern of rectal temperature Summer season. Journal of Dairy Science, Savoy, v.68, n.4, p.979-985, 1992.

ISAAKS, E.H.; SRIVASTAVA, R.M. An introduction to applied geoestatistics. New York: Oxford University, 1989. 561p.

JOHNSON, H. Environmental management of cattle to minimize the stress of climatic change. International Journal of Biometeorology, Oxford, v.24, n.1, p.65-78, 1980.

LITTLE, T.M.; HILLS, F.J. Agricultural experimentation. New York: John Wiley \& Sons, 1978. 350p.

MILES, D.M. et al. Winter broiler litter gases and nitrogen compounds: temporal and spatial trends. Atmospheric Environment, Amsterdam, v.42, n.14, p.3351-3363, 2008.

NÄÄS, I.A. Biometeorologia e construções rurais em ambiente tropical. In: CONGRESSO BRASILEIRODE BIOMETEOROLOGIA, 2., 1998, Goiânia. Anais... Goiânia: Sociedade de Biometeorologia, 1998. p.63-73.

PERISSINOTTO, M. et al. Efeito da utilização de sistemas de climatização nos parâmetros fisiológicos do gado leiteiro. Engenharia Agrícola, Jaboticabal, v.26, n.3, p.663-671, 2006.

ROSEMBERG, L.G. et al. Human and animal biometeorology. Microclimate - the biological environment. 2.ed. New York: Wiley-Interscience, 1983. p.425-467.

SCHLOTZHAVER, S.D.; LITTELL, R.C. SAS: system for elementary statistical analysis. 2. ed. Cary, 1997. 905p.

SOUZA, S.R.L. et al. Análise das condições ambientais em sistemas de alojamento "freestall” para bovinos de leite. Revista Brasileira de Engenharia Agrícola e Ambiental, Campina Grande, v.8, n.2-3, p.299-303, 2004.

TRANGMAR, B.B. et al. Applications of geostatistics to spatial studies of soil properties. Advances in Agronomy, New York, v.38, n.1, p.45-94, 1985.

VANNI, S.M. Modelos de regressão: estatística aplicada. São Paulo: Legmar Informática \& Editora, 1998. 177p.

VIEIRA, S.R. Geoestatística em estudos de variabilidade espacial do solo. In: NOVAIS, R.F. et al. (Eds.). Tópicos em ciência do solo. Viçosa: Sociedade Brasileira de Ciência do Solo, 2000, V.1, p.1-53.

WARRICK, A.W.; NIELSEN, D.R. Spatial variability of soil physical properties in the field. In: HILLEL, D. (Ed.). Applications of soil physics. New York: Academic, 1980. p.319-344. 